\title{
Comestão
}

\section{Análise das influências intelectuais na produção científica da área de Ciência da Informação: um estudo sobre os bolsistas de produtividade em pesquisa (PQ-CNPq)}

\author{
Leilah Santiago Bufrem \\ Doutora; Universidade Federal de Pernambuco, Recife, PE, Brasil; \\ santiagobufrem@gmail.com \\ Fábio Mascarenhas e Silva \\ Doutor; Universidade Federal de Pernambuco, Recife, PE, Brasil; \\ fabiomascarenhas@gmail.com \\ Natanael Vitor Sobral \\ Doutorando; Universidade Federal da Bahia, Salvador, BA, Brasil; \\ natanvsobral@gmail.com
}

\begin{abstract}
Resumo: Busca investigar as bases intelectuais dos bolsistas de produtividade em pesquisa do Conselho Nacional de Desenvolvimento Científico e Tecnológico da área de Ciência da Informação por meio das suas citações. Para compor o corpus do estudo, elege a Base Referencial de Artigos de Periódicos em Ciência da Informação, considerando o recorte temporal de 1972 até 2015. Adota como procedimentos metodológicos: (1) identificação dos bolsistas de produtividade em pesquisa da área de Ciência da Informação; (2) coleta de dados na Base Referencial de Artigos de Periódicos em Ciência da Informação (registros acrescidos das referências); (3) processamento dos dados, por meio de sua padronização, arrolamento e classificação no software VantagePoint; e (4) análise e apresentação de relações entre os citantes, os citados e os temas. Apresenta entre os principais resultados as obras de Castells (1999), Dahlberg (1978), Wersig (1993) e Meadows (1999) como as mais referenciadas pelos pesquisadores estudados. Ao recortar as 35 obras mais citadas, observa que aproximadamente $2 / 3$ são de origem estrangeira, o que demonstra o peso da literatura internacional como referencial do grupo. Constata que 11 das 35 obras mais citadas $(31,4 \%)$ são dos próprios bolsistas de produtividade em pesquisa da área de Ciência da Informação, sendo que $60,6 \%$ das citações a essas obras são realizadas pelos congêneres de bolsa, o que sugere a existência de reconhecimento mútuo entre os pares. Por fim, verifica que Tecnologias da Informação e Comunicação, Biblioteca, Indexação e Bibliometria são os temas mais representativos, e que a obra de Dahlberg (1978) é a de maior influência nos trabalhos ligados às Ontologias e à Organização do Conhecimento.
\end{abstract}

Palavras-chave: Produtividade em pesquisa. Ciência da informação. Análise de citações. Influências intelectuais. Cientometria. 

da área de Ciência da Informação: um estudo sobre os bolsistas de produtividade em pesquisa (PQ-CNPq) Leilah Santiago Bufrem, Fábio Mascarenhas e Silva, Natanael Vitor Sobral

\section{Introdução}

Marcada pelo dinamismo das relações entre as práticas de produção e comunicação científica e o seu potencial de representatividade, a produção individual e coletiva da literatura científica, elemento substantivo de práticas institucionalizadas, vem gerando e renovando domínios, de modo a legitimar a cultura científica.

Enquanto área do conhecimento científico, a Ciência da Informação (CI) no Brasil é composta por elementos que a caracterizam como espaço de produção de saberes consolidados, buscando atender as demandas de cunho acadêmico e profissional que circundam o universo da informação através de práticas disciplinares e interdisciplinares. Dentre os elementos constituintes da CI, destacam-se os formativos, compostos por programas de graduação e pósgraduação que promovem o ensino, a pesquisa e a extensão na área; os representativos, que englobam as associações, os modos de comunicação e os eventos que discutem a organização comunitária e a representatividade do campo em esfera social; e, por fim, os elementos avaliativos, que convergem para o fortalecimento das estruturas formais, institucionalização social do campo, regramento e adequação da área aos critérios de qualidade científica.

Destaca-se nesse contexto o Conselho Nacional de Desenvolvimento Científico e Tecnológico $(\mathrm{CNPq})^{1}$, criado em 1951 para formular e conduzir políticas de ciência, tecnologia e inovação (BRASIL, 2015). Sua atuação vem contribuindo para a formação e o reconhecimento das instituições de pesquisa e dos pesquisadores brasileiros, e, entre os instrumentos que convergem para esse intento, as bolsas de produtividade em pesquisa são destinadas aos pesquisadores que se destacam entre seus pares. Com a proposta de valorizar a produção científica segundo critérios normativos, estabelecidos pelo órgão, e específicos, pelos Comitês de Assessoramento (CA), as bolsas são distribuídas aos pesquisadores que constituem a elite da produção científica no país, pois, além de outros critérios, os bolsistas devem se dedicar ao cumprimento dos propósitos constantes em seu 
projeto de pesquisa, mantendo atividades acadêmico-científicas oficialmente vinculadas a instituições de pesquisa e ensino.

Com essas características, as produções científicas desses pesquisadores podem ser consideradas paradigmáticas pela comunidade do campo específico do conhecimento, e suas relações concretas podem ser visualizadas por meio de redes de citações que se estendem desde os autores fundantes até os pesquisadores que trataram do assunto mais recentemente. Diante dessas possibilidades de reconhecimento e valorização da pesquisa publicada por essa elite intelectual, cujas atividades acadêmico-científicas estão oficialmente vinculadas a instituições de pesquisa e ensino, surgem questões relacionadas às condições específicas em que ocorrem essas produções, aos seus modos de relacionamento, entre si ou com temas e linhas de pesquisa delineados na CI, e às aproximações ou distanciamentos entre autores, temas e linhas teóricas.

Desse modo, objetiva-se neste trabalho investigar as bases intelectuais dos bolsistas de produtividade em pesquisa (PQ-CNPq) da área de $\mathrm{CI}$ por meio das citações. Para a realização deste estudo, elegeu-se a Base Referencial de Artigos de Periódicos em Ciência da Informação (Brapci)², atualmente com 41 periódicos, entre correntes e históricos e 9.992 artigos indexados ${ }^{3}$. Escolheram-se as revistas científicas como documentos de análise porque os artigos de periódicos, enquanto frutos de pesquisa e reflexão e de posterior avaliação por uma comissão científica, são fontes privilegiadas de produção de conhecimento científico certificado. O recorte temporal considerado neste artigo foi de 1972 até 2015, excluindo-se 2016 por ser o ano em andamento e pelo fato de que o corpo de PQ-CNPq que compõe o universo é do quadro de pesquisadores vigente em 2015.

\section{Quadro teórico}

Esta seção está subdividida em duas outras. A primeira trata da Ciência como conjunto de práticas socialmente construídas, com ênfase nas relações de citação enquanto formas de reconhecimento que apenas se satisfazem na coletividade em processos de anexação. A segunda subseção discute as influências intelectuais, 

da área de Ciência da Informação: um estudo sobre os bolsistas de produtividade em pesquisa (PQ-CNPq) Leilah Santiago Bufrem, Fábio Mascarenhas e Silva, Natanael Vitor Sobral

ressaltando os aspectos genealógicos e a construção de grupos sociais acadêmicos que se organizam com a intenção de reafirmar posicionamentos afins sob a influência de algum fundante.

\subsection{A Ciência como conjunto de práticas socialmente construídas}

Ao argumentar que a Ciência é um conjunto de práticas socialmente construídas na tentativa de descobrir progressivamente as estruturas causais da realidade, Lloyd (1995) se refere à definição de critérios de cientificidade para a análise e compreensão de uma construção científica. Essa posição permite melhor “[...] compreender as explicações e o emprego de arcabouços que incluem pressupostos metodológicos e filosóficos" (LLOYD, 1995, p. 150). Mas para que se adquira a compreensão de uma construção científica, impõe-se a reflexão sobre as relações que se verificam no campo do conhecimento específico e as repercussões e transformações que delas decorrem. Esse processo de transformações sociais é enfatizado por Lloyd (1995, p. 18) na defesa que faz do pensamento analítico para o exame dos "[...] sistemas conceituais, da lógica de investigação e de raciocínio empregada por certas ciências e do modo como algumas delas avançam mais do que outras.”. O argumento de Lloyd (1995) é uma forma de estímulo ao processo de compreensão da lógica de investigação e do arcabouço do fazer científico, como o que leva o pesquisador a uma elaborada análise para compreensão e reconstrução de investigações precedentes.

Como elemento constitutivo desse arcabouço, a citação é uma forma de expressão do autor no conjunto de relações de produção em determinado campo do conhecimento. Nesse contexto, sua legitimidade está sujeita ao sistema de relações históricas e sociais em que se insere. Assim, as práticas comunicativas de uma sociedade são afetadas pelas suas condições de existência e sua legitimação decorre das relações que os produtores de bens simbólicos mantêm entre si (BOURDIEU; PASSERON; CHAMBOREDON, 1969, p. 59).

A referência ao conhecimento publicado, ou citação, resulta do direito inerente a qualquer autor de citar a outro ou a si mesmo, pressupondo um juízo de 
valor, um discernimento que pode traduzir caução teórica, aprovação, dependência ou desaprovação. Mas mesmo nesse último caso, a referência traduz o reconhecimento de que o autor citado é autoridade no campo específico do saber que trata e faz parte de um contexto em que as manifestações críticas são determinantes para o aprimoramento dos resultados do trabalho intelectual.

$\mathrm{Na}$ literatura, são vários os estudos de citação, em diversos enfoques e perspectivas. Garfield (1955) inicia uma verdadeira revolução ao propor uma técnica para a organização de referências bibliográficas que visava sistematizar as citações, associando autores citados e citantes, com o intuito de facilitar a busca de "descendentes bibliográficos" dos artigos, de modo similar ao que existe na atualidade, nas principais bases de dados científicas, superando o modelo das notas de rodapé, fortemente utilizado nos livros. Em contrapartida, Franck (1999) e Smith (2006) ressaltam a perspectiva de poder existente nos índices de citações. Nesses rankings, aqueles que possuem mais citações serão percebidos pela comunidade como os melhores cientistas, e isso favorece a criação de cartéis de citações (FRANCK, 1999).

Esses cartéis podem ser construídos por avaliadores e editores que determinam os textos que serão publicados, nem sempre por critérios éticos, visando manipular os índices de citações e as posições de prestígio, e também por pesquisadores que dispõem da moeda da atenção, uma taxa paga através das trocas simbólicas de citações. Esse tem sido um dos principais sistemas de acúmulo de capital utilizados pela academia (FRANCK, 1999).

Desse modo, as relações de citação não devem ser analisadas sob o enfoque do "puritanismo científico" ou da honra ao mérito. Há sobremaneira uma perspectiva de poder ocultada por trás dos princípios éticos de avaliação cega por pares, em que os detentores dos veículos de produção, em associação com os autores e avaliadores, podem subverter a lógica, tendo em vista sua posição de autonomia, fortemente pressionada pela necessidade de acúmulo de capital científico imposta pelos imperativos do "publicar ou perecer", "comunicar ou perecer" e "ser citado ou perecer". 

da área de Ciência da Informação: um estudo sobre os bolsistas de produtividade em pesquisa (PQ-CNPq) Leilah Santiago Bufrem, Fábio Mascarenhas e Silva, Natanael Vitor Sobral

Segundo argumento de Bourdieu (1987, p. 170), os estudos de citação, denominados de citatologia, ignoram, geralmente, a questão política relacionada às verdadeiras batalhas travadas nos campos culturais, o que os impede de caminhar além das relações mais aparentes. Detêm-se nas referências explícitas, ou seja, somente na face visível das referências realmente efetuadas, tanto para o produtor como para o público. Sua função tem sido determinar índices de conhecimento, podendo definir eventualmente “[...] relações de lealdade ou dependência, de estratégias de filiação ou de anexação.”.

Assim, entende-se que os estudos de citação devem ser empreendidos com cautela, em especial aqueles que buscam classificar os pesquisadores em estratos numéricos e estabelecer relações da quantidade com a qualidade, sem necessariamente compreender o contexto da produção e confrontar os dados com os eventos sociais de natureza qualitativa que determinam as posições dos atores nas redes configuradas.

\subsection{Genealogia e influências intelectuais na produção de conhecimento}

Os estudos de genealogia no contexto acadêmico têm se revelado como importantes ferramentas para investigar a origem, evolução e disseminação de áreas do conhecimento (MENA-CHALCO, 2016). O objeto da pesquisa genealógica está ligado à investigação dos ascendentes e descendentes de um indivíduo. A identificação dos graus de vínculos entre os indivíduos pode ser encontrada nos registros históricos, ou seja, em documentos que forneçam indícios de suas ligações (ROSSI; MENA-CHALCO, 2014).

Considerando a Ciência como um sistema social (BRAGA, 1974; MACIAS-CHAPULA, 1998; RADNITZKY, 1970), entende-se que os pesquisadores se associam em um amplo espectro de situações, que podem ser estabelecidas para atender um objetivo pontual de um determinado momento de uma pesquisa ou, mesmo, numa relação de vida, em que concepções concretas são construídas em conjunto, havendo um laço profundo entre os sujeitos que se materializa no partilhar de uma posição intelectual ou de uma teoria que se 
registra na produção de conhecimento, sendo transmitidas de geração em geração entre os pares congêneres — o que pressupõe a formulação de redes genealógicas.

Ao analisar a organização grupal de pesquisadores com posicionamentos afins, Burke (2012) argumenta que as histórias intelectuais dos séculos XIX e XX fazem referências constantes às "escolas de pensamento". Segundo o autor, essas escolas, por vezes, estão associadas a um indivíduo, como, por exemplo, a escola de geografia de Ratzel, ou também podem estar associadas a lugares e instituições, como o exemplo das escolas de teoria crítica de Frankfurt e de sociologia e economia de Chicago (BURKE, 2012). É dessa lógica de organização social que surgem os cientistas que se autodenominam ou são reconhecidos pela comunidade acadêmica como "mertonianos", "marxistas", "weberianos", entre outros, a depender do fundante das ideias.

Na Ciência Moderna, com o advento do periódico científico e com a ampliação das formas de conhecimento registrado, as relações de associação entre os autores se tornaram mais evidentes por meio das citações realizadas nos manuscritos. Nessa dinâmica de reconhecimento, os citantes se referem frequentemente aos seus influenciadores (citados), discutindo suas ideias, reproduzindo suas teorias e reforçando seus pressupostos em contextos diversos, o que amplia a voz do seu predecessor e mantém ativo o conhecimento produzido ao longo da história.

Obviamente, é comum a existência de conflitos entre as escolas de pensamento, o que estimula a produção de citações negativas, cujo propósito é criticar o trabalho de determinados autores que divergem da corrente intelectual do citante. Em uma perspectiva endógena, nota-se que as próprias escolas de pensamento produzem divergências entre seus membros, gerando divisões entre os "filhos" de uma mesma herança intelectual, que ao discordarem de especificidades da obra de seus patriarcas fundam subcorrentes com via própria e um conjunto de associados (irmãos).

Como afirma Burke (2012), as escolas de pensamento são mais unidas para quem olha de fora, pois dentro delas há diversos conflitos. Essa configuração 

da área de Ciência da Informação: um estudo sobre os bolsistas de produtividade em pesquisa (PQ-CNPq) Leilah Santiago Bufrem, Fábio Mascarenhas e Silva, Natanael Vitor Sobral

social se assemelha aos traços das perspectivas biológica e social de uma família, em que filhos podem surgir por uma relação formal de orientação ou pelo ato de "adoção científica", e as gerações vão se organizando em irmãos, filhos, netos e bisnetos que descendem da parentela de um acadêmico seminal, por isso a importação do termo genealogia.

Montoye e Washburn (1980), ao estudarem a genealogia acadêmica afirmaram que esta serve para traçar a herança erudita de um determinado grupo de pesquisadores. Essa herança é transmitida por um processo de influência intelectual, que se manifesta na transmissão de ideias entre ascendentes e descendentes, podendo também assumir configurações distintas, tais como: autores mais jovens influenciando autores mais velhos, discípulos influenciando mestres e contemporâneos que se influenciam. Assim, ao se observar a face material das transmissões dessas concepções intelectuais na produção de conhecimento, podem ser encontradas situações diversas, diferentes das relações biológicas, em que o avô sempre será mais velho que o pai, e o pai, sempre mais velho do que o filho.

Sugimoto (2014), Mena-Chalco (2016) e Lubek et al. (1995), ao discutirem os estudos de genealogia, fizeram distinção conceitual quanto aos tipos, identificando a existência das genealogias acadêmica, intelectual e científica, conforme se pode observar no Quadro 1.

Quadro 1 - Tipos de genealogia nos estudos de produção científica.

\begin{tabular}{|l|l|}
\hline Tipos & Definição \\
\hline $\begin{array}{l}\text { Genealogia } \\
\text { Acadêmica }\end{array}$ & $\begin{array}{l}\text { Usada para descrever as relações formais de orientação (em } \\
\text { geral, orientações de doutorado). }\end{array}$ \\
\hline $\begin{array}{l}\text { Genealogia } \\
\text { Científica }\end{array}$ & $\begin{array}{l}\text { Usada para descrever estudos no nível de ciência (relatar } \\
\text { histórias de descobertas científicas e estudos de familiares } \\
\text { na ciência). }\end{array}$ \\
\hline $\begin{array}{l}\text { Genealogia } \\
\text { Intelectual }\end{array}$ & $\begin{array}{l}\text { Usada para descrever influência intelectual (não } \\
\text { necessariamente um orientador formal ou institucional - } \\
\text { podem ser influências intelectuais não institucionalizadas). }\end{array}$ \\
\hline
\end{tabular}

Fonte: Adaptado de Sugimoto (2014), Mena-Chalco (2016), Lubek et al. (1995).

Sobre o quadro supracitado, na área de CI destaca-se o estudo de Sugimoto et al. (2011), que utilizando dados de genealogia acadêmica analisaram teses de doutorado em Biblioteconomia e CI. O foco do estudo foi 

da área de Ciência da Informação: um estudo sobre os bolsistas de produtividade em pesquisa (PQ-CNPq) Leilah Santiago Bufrem, Fábio Mascarenhas e Silva, Natanae/ Vitor Sobral

analisar as redes interdisciplinares estabelecidas pela influência dos orientadores e membros da banca nas teses de doutorado dos alunos. Russel e Sugimoto (2009) afirmam que a genealogia acadêmica é valiosa porque fornece contexto, história e tem potencial para prever as tendências futuras em uma disciplina ou campo particular. Destacando que há poucos estudos desenvolvidos sobre o tema, os autores revelam que a maior parte das publicações é de trabalhos que traçaram a linhagem de algum estudioso contemporâneo ou a exploração da árvore genealógica de algum patriarca notório da Ciência (RUSSEL; SUGIMOTO, 2009).

Ao discutir a genealogia científica, Andraos (2005) afirma que esses estudos são de interesse para os cientistas experientes e jovens, em especial para a compreensão da evolução da história científica, a identificação de padrões entre as descobertas e o reconhecimento de conexões entre os pesquisadores. Nesse estudo, Andraos (2005) também considerou as relações de doutoramento, pósdoutoramento, as conexões entre ideias e o fluxo de conhecimento entre países. Seu objetivo foi evidenciar as contribuições feitas por cientistas que trabalharam em laboratórios de universidades canadenses e do Conselho Nacional de Pesquisa do Canadá nas áreas de Física e Química.

$\mathrm{Na}$ genealogia intelectual, é comum o uso da análise de citações para identificar e compreender o fluxo das ideias (SAFER; TANG, 2009). Conforme sugere Sirnelli (2003), o esclarecimento das genealogias de influências intelectuais busca analisar os intelectuais que atuaram como "despertadores" para uma geração. Esses agentes representam "um fermento" para as gerações intelectuais seguintes (SIRNELLI, 2003). Ao investigarem as genealogias intelectuais no contexto organizacional, Ikeda et al. (2002) argumentaram que essas relações se constroem a partir da abstração de uma estrutura causal de eventos de conhecimento. O gráfico de genealogia intelectual é útil para indivíduos e organizações examinarem as condições atuais de conhecimento em uma instituição e para esclarecer o papel intelectual de indivíduos, organizações e documentos no contexto em que se situam. Assim, notam-se os diversos papéis dos estudos de genealogia intelectual nas humanidades e na gestão. 

da área de Ciência da Informação: um estudo sobre os bolsistas de produtividade em pesquisa (PQ-CNPq) Leilah Santiago Bufrem, Fábio Mascarenhas e Silva, Natanae/ Vitor Sobral

Sobre a investigação da genealogia intelectual no contexto acadêmico, Hutson (2006) percebeu em seu estudo que muitos autores fizeram citações para professores, orientadores e colegas de turma. Em sua percepção, o ato de citar os congêneres intelectuais é uma forma de citar a si mesmo, tendo em vista que a autocitação pode ser entendida numa perspectiva relacional, e não apenas individual. Em sua constatação empírica, a título de exemplo, Hutson (2006) percebeu que em um determinado paper, o autor havia realizado 685 citações, e que destas, 72 eram autocitações (10,5\%). O documento também continha 68 citações ao seu orientador, 30 citações a outros orientadores de pós-graduação, 87 citações a outros arqueólogos que se formaram a partir da mesma instituição e 15 citações a colegas que colaboram no trabalho na mesma sub-região arqueológica (HUTSON, 2006).

Como ressalta o próprio Hutson (2006), embora seu estudo tenha sido em um contexto circunscrito e com um universo muito pequeno, vale a pena se aprofundar na análise do extended self, ou seja, o "eu estendido", que pode ser definido como as citações que os autores fazem aos seus entes genealógicos mais próximos que representam suas posições intelectuais.

Neste estudo, optou-se por trabalhar com a genealogia intelectual, tendo em vista que a problematização do artigo está posta sobre a questão do fluxo genealógico intelectual dos PQ-CNPq em CI, buscando-se entender quais são as principais influências intelectuais utilizadas a partir da técnica de análise de citações.

Sob o aspecto da representação gráfica da genealogia intelectual em árvores genealógicas, cada vértice representa um indivíduo na árvore e cada aresta indica a existência de algum tipo de relação entre os vértices. Cada citado e citante é representado por vértices, e as arestas direcionadas significam as direções dos fluxos de influência intelectual. Um conjunto de árvores genealógicas é comumente denominado de floresta (ROSSI; MENA-CHALCO, 2014). Essa técnica é importante para a verificação de aspectos centrais nos estudos genealógicos, tais como os anos das citações, as gerações e outros atributos 

da área de Ciência da Informação: um estudo sobre os bolsistas de produtividade em pesquisa (PQ-CNPq) Leilah Santiago Bufrem, Fábio Mascarenhas e Silva, Natanael Vitor Sobral

importantes, como os países, instituições e temas, entre outras variáveis passíveis de análise.

A possibilidade de apresentar as genealogias em âmbito científico por meio da técnica de análise de redes sociais (ARS) é defendida por Jordan (2016), que demonstra ser possível visualizar as redes de citações entre as influências intelectuais e os seus citantes e perceber os pares que compartilham mesmos textos e autores. O autor destaca, também, atributos de dados como o nível de bolsa, a nacionalidade dos citados e dos citantes, o quantitativo de produções e a intensidade das relações de citações, sendo que esse último fator auxilia na compreensão da força da influência intelectual entre autores.

\section{Percurso metodológico}

Distinguem-se quatro fases relativas aos procedimentos metodológicos desenvolvidos para a construção deste artigo, a saber:

a) identificação dos PQ-CNPq da área de CI: foi utilizada a página eletrônica de bolsas e auxílios vigentes do $\mathrm{CNPq}^{4}$. A busca foi realizada conforme a seguinte expressão: País (Brasil) AND Estado (Todos os Estados) AND Instituições (Todas as Instituições) AND Grandes Áreas (Ciências Sociais Aplicadas) AND Áreas (Ciência da Informação) AND Modalidades (Produtividade em Pesquisa) AND Níveis (Todos os Níveis). A data da busca foi 31 de dezembro de 2015. Com isso, identificou-se um universo composto por um pesquisador Sênior (PQSR), 20 pesquisadores PQ-1 e 25 pesquisadores PQ-2, totalizando 46 pesquisadores;

b) coleta de dados na Brapci: para isso, acessou-se a Brapci. Visando evitar a possibilidade de perda de informações decorrentes da representação variada dos nomes foram procedidas rodadas de buscas. Na primeira rodada, buscou-se o nome completo do pesquisador, por exemplo: "Leilah Santiago Bufrem”. Na segunda rodada, foram combinados o primeiro e o último nome do pesquisador, exemplo: "Leilah Bufrem". Por fim, visando 

da área de Ciência da Informação: um estudo sobre os bolsistas de produtividade em pesquisa (PQ-CNPq) Leilah Santiago Bufrem, Fábio Mascarenhas e Silva, Natanael Vitor Sobral

assegurar que nenhum trabalho deixaria de ser recuperado, a busca foi realizada considerando apenas o último sobrenome do PQ-CNPq, exemplo: "Bufrem". Esses procedimentos tiveram sua necessidade observada no projeto que responde por este artigo, e tiveram a intenção de evitar que registros importantes deixassem de ser considerados. Ademais, ao analisar a lista de artigos recuperados nas buscas, foram considerados apenas aqueles que, de fato, são de autoria ou coautoria do referido PQ-CNPq. Todos os dados foram obtidos no formato de metadados (acrescidos das referências). Em seguida, os registros foram tabulados em uma planilha eletrônica, considerando-se os artigos publicados no período de 1972 até 2015. O processo de coleta de referências foi realizado de maneira manual. O corpus da pesquisa é composto por 1.009 artigos de periódicos e 16.934 referências. A coleta foi realizada entre os meses de janeiro e maio de 2016;

c) processamento dos dados: nesse momento, os dados foram padronizados, relacionados e classificados no software VantagePoint ${ }^{5}$. Optou-se pelo formato de matrizes, tendo em vista a necessidade de mapear as relações entre os autores citados, citantes e os temas. A classificação dos dados se deu através da criação dos seguintes campos: autor (AU), título (TI), periódico (JO), ano de publicação (PY), referências (RE) e palavras-chave $(\mathrm{KW})$. A estrutura relacional permitiu que os dados fossem interpretados a partir da observação de coocorrências;

d) análise de relações: buscou-se aqui apresentar as relações entre os citantes, os citados e os temas, por meio do software UCINET/NetDraw ${ }^{6}$. Para isso, a técnica de ARS foi utilizada, visando expressar os vínculos, os pesos e atributos inerentes às relações. Nessa etapa, optou-se por converter o rótulo com os nomes dos PQ-CNPq em códigos. Isso ajudou a preservar a identidade dos atores, chamando a atenção para os comportamentos do grupo analisado, eximindo-se de questões pessoais e análises individualizadas que fugissem do foco da pesquisa. 

da área de Ciência da Informação: um estudo sobre os bolsistas de produtividade em pesquisa (PQ-CNPq) Leilah Santiago Bufrem, Fábio Mascarenhas e Silva, Natanael Vitor Sobral

\section{Resultados e discussão}

Os resultados estão estruturados na seguinte ordem: (1) obras mais citadas pelos PQ-CNPq, conforme Quadro 2; (2) relações entre os PQ-CNPq e os autores mais citados, segundo Figura 1; (3) citações nas 11 obras mais citadas dos PQ-CNPq; e (4) relação entre os dez autores mais citados pelos PQ-CNPq com os 30 temas mais frequentes.

A priori, buscou-se compreender o quadro de obras citadas mais representativas na produção dos PQ-CNPq em CI indexadas na Brapci (1972 a 2015). O Quadro 2 apresenta o livro A sociedade em rede, de Manuel Castells, como o mais citado. Tendo em vista o alto prestígio obtido pelo autor nas Ciências Sociais, esse dado não surpreende. Segundo estudo promovido pelo próprio Castells (2016b) no Social Science Citation Index ${ }^{7}$, considerando o período de 2000 a 2015, apenas os autores vivos, verificou-se que Castells é o quarto autor mais citado, ficando apenas atrás de Anthony Giddens, Robert Putnam e Jürgen Habermas, respectivamente. Destaca-se ainda que a posição proeminente do autor o coloca à frente de importantes nomes das Ciências Sociais, tais como: Douglas Massey, Mark Granovetter, Zygmunt Bauman, Saskia Sassen, Doug McAdam e vários outros.

Nesse mesmo estudo, ao delimitar apenas os autores da área de Comunicação, Castells obteve destaque ainda maior, sendo o primeiro colocado, superando nomes como: Elihu Katz, Robert Entman, George Gerbner e Henry Jenkins, respectivamente (CASTELLS, 2016a).

Quadro 2 - Dez obras mais citadas pelos PQ-CNPq da área de CI.

\begin{tabular}{|l|c|l|l|}
\hline Autor & Citações & Referência \\
\hline Castells (1999) & 42 & $\begin{array}{l}\text { CASTELLS, M. A sociedade em rede. São Paulo: Paz e } \\
\text { Terra, 1999. }\end{array}$ \\
\hline Dahlberg (1978) & 34 & $\begin{array}{l}\text { DAHLBERG, I. Teoria do conceito. Ciência da } \\
\text { Informação, v. 7, n. 2, 1978. }\end{array}$ \\
\hline Wersig (1993) & 34 & $\begin{array}{l}\text { WERSIG, G. Information science: the study of postmodern } \\
\text { knowledge usage. Information Processing \& } \\
\text { Management, v. 29, n. 2, p. 229-239, 1993. }\end{array}$ \\
\hline Meadows (1999) & 33 & $\begin{array}{l}\text { MEADOWS, A. J. A comunicação científica. Brasília: } \\
\text { Briquet de Lemos/Livros, 1999. }\end{array}$ \\
\hline Saracevic (1996) & 29 & $\begin{array}{l}\text { SARACEVIC, T. Ciência da informação: origem, evolução } \\
\text { e relações. Perspectivas em Ciência da Informação, Belo } \\
\text { Horizonte, n. 1, v. 1, p. 41-62, jan./jun., 1996. }\end{array}$ \\
\hline
\end{tabular}




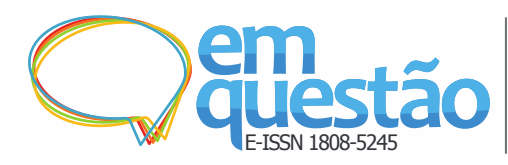

Análise das influências intelectuais na produção científica da área de Ciência da Informação: um estudo sobre os bolsistas de produtividade em pesquisa (PQ-CNPq) Leilah Santiago Bufrem, Fábio Mascarenhas e Silva, Natanael Vitor Sobral

\begin{tabular}{|l|c|l|}
\hline Farradane (1980) & 27 & $\begin{array}{l}\text { FARRADANE, J. Knowledge, Information, and information } \\
\text { science, Journal of Information Science, v. 2, n. 2, 1980. }\end{array}$ \\
\hline Choo (2003) & 25 & $\begin{array}{l}\text { CHOO, C. W. A organização do conhecimento: como as } \\
\text { organizações usam a informação para criar significado, } \\
\text { construir conhecimento e tomar decisões. São Paulo: Senac } \\
\text { São Paulo, 2003. }\end{array}$ \\
\hline Le Coadic (1996) & 25 & $\begin{array}{l}\text { LE COADIC, Y-F. A Ciência da informação. Brasília: } \\
\text { Briquet de Lemos, 1996. }\end{array}$ \\
\hline Davenport (1998) & 24 & $\begin{array}{l}\text { DAVENPORT, T. H. Ecologia da informação: porque só a } \\
\text { tecnologia não basta na era da informação. São Paulo: } \\
\text { Futura, 1998. }\end{array}$ \\
\hline Hjørland (2002) & 24 & $\begin{array}{l}\text { HJØRLAND, B. Domain analysis in information science: } \\
\text { eleven approaches - traditional as well as innovative. } \\
\text { Journal of Documentation, v. 58, n. 4, p. 422- 462, 2002. }\end{array}$ \\
\hline
\end{tabular}

Fonte: Dados da pesquisa.

Ao observar o grupo de autores mais citados, nota-se que os resultados corroboram outros estudos já realizados. Freitas, Nascimento e Bufrem (2014) já haviam identificado a proeminência de Dahlberg no quesito citações em pesquisa desenvolvida na Brapci. Araújo et al. (2007) investigaram os autores mais prestigiados por professores e pesquisadores brasileiros em CI, e constataram que os nomes de Saracevic, Le Coadic e Hjørland são bastante lembrados. Silveira et al. (2013) ao analisarem os domínios científicos da CI representados no GT 7 (Produção e Comunicação da Informação em Ciência, Tecnologia \& Inovação) da Associação Nacional de Pesquisa e Pós-Graduação em Ciência da Informação $\left(\right.$ Ancib) ${ }^{8}$ perceberam o destaque de Meadows. Já Kroef et al. (2015) identificaram que na temática de Gestão da Informação, Davenport e Choo são os autores mais citados, com amplo destaque. E, por fim, Farradane, importante autor da área de CI, constituindo-se um dos importantes fundantes, vem sendo citado intensivamente por dois PQ-CNPq que compõem o estudo e, por isso, aparece nas primeiras colocações do ranking.

Chama a atenção que dentre as dez obras mais citadas, cinco são artigos e cinco são livros, demonstrando equilíbrio nas tipologias mais referenciadas. Outro aspecto que merece ser ressaltado é o perfil clássico das obras. Apenas dois textos foram produzidos no século XXI. Tal comportamento pode ser associado à necessidade que os PQ-CNPq têm em apresentar literaturas de autores fundantes em seus artigos, privilegiando aqueles a quem o pioneirismo é atribuído em determinados subtemas da área de CI. 

da área de Ciência da Informação: um estudo sobre os bolsistas de produtividade em pesquisa (PQ-CNPq) Leilah Santiago Bufrem, Fábio Mascarenhas e Silva, Natanael Vitor Sobral

Sob o aspecto temático, entre as dez obras mais citadas constata-se que os assuntos mais representativos são: Fundamentos da CI (quatro), Organização da Informação e do Conhecimento (dois), Gestão da Informação e do Conhecimento (dois), Sociedade da Informação (um) e Comunicação Científica (um).

Ao ampliar o recorte e considerar as 35 obras mais citadas, percebe-se que $23(65,7 \%)$ são estrangeiras e 12 (34,3\%) são nacionais (ver Figura 1). Apesar de o percentual de literatura nacional ser representativo, nota-se a predileção por textos internacionais, o que reflete a necessidade que os autores paradigmáticos do campo têm de dialogar com as fontes internacionais de conhecimento. Sobre isso, Araújo et al. (2007) perceberam, em estudo correlato com pesquisadores e professores da área de CI, que entre os autores mais citados predominam os estrangeiros, mas também há uma significativa presença de autores brasileiros. Entre os estrangeiros citados, destacam-se alguns que já estiveram no Brasil para eventos, palestras ou orientações. Os autores do estudo sugerem que tal fator pode ser um potencializador das citações (ARAÚJO et al., 2007). Tal percepção reforça as justificativas da presença dos nomes de Castells, Meadows, Saracevic, Davenport, Hjørland e, também, Farradane e Le Coadic, esses dois últimos, respectivamente, atuaram como orientador de mestrado e examinador de doutorado de um bolsista PQ-CNPq cada, fora do Brasil. 
Análise das influências intelectuais na produção científica da área de Ciência da Informação: um estudo sobre os bolsistas de produtividade em pesquisa (PQ-CNPq)

Leilah Santiago Bufrem, Fábio Mascarenhas e Silva, Natanael Vitor Sobral

Figura 1 - Relações entre os PQ-CNPq e os 35 autores mais citados por eles.

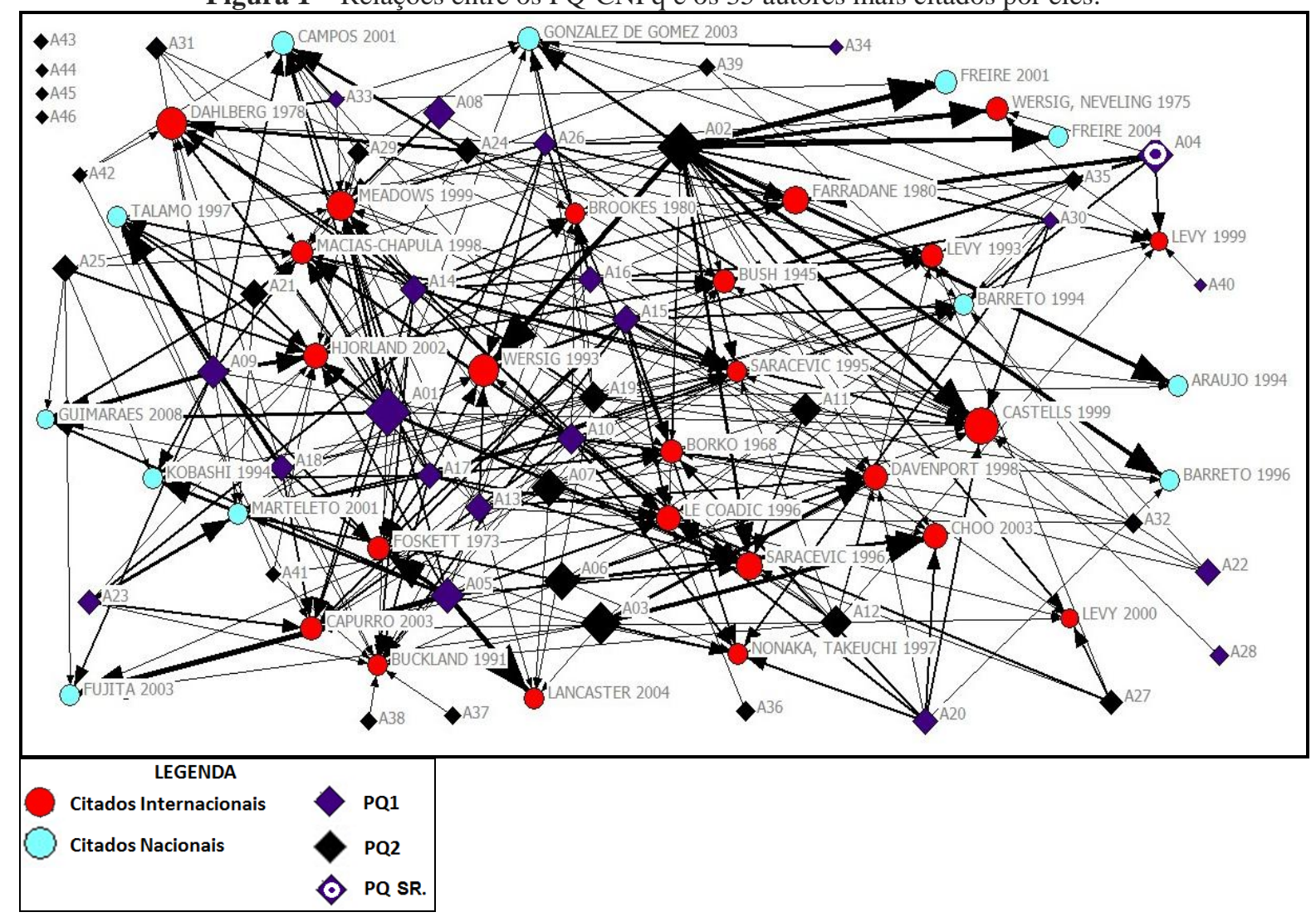

Fonte: Dados da pesquisa.

Ademais, evidenciou-se que 11 das 35 obras mais citadas $(31,4 \%)$ pertencem aos próprios $\mathrm{PQ}-\mathrm{CNPq}$, o que sugere a princípio uma relação de prestígio aos pares na produção de conhecimento, mais especificamente no ato de citar. Verificou-se, ainda, que quatro pesquisadores (A43, A44, A45 e A46), divergindo dos demais, não citam quaisquer das 35 obras mais citadas pelo grupo de PQ-CNPq (ver Figura 1), demonstrando que seguem influências intelectuais diferentes, na contramão do núcleo hegemônico.

Conforme se verifica no tamanho dos ícones (ver Figura 1), os PQ-CNPq com maior produção na Brapci são A01 (57), A02 (57), A03 (47), A04 (42), A05 (38), A06 (38), A07 (38), A08 (35), A09 (34) e A10 (33). Entre os dez mais representativos, constatou-se que cinco são PQ1, quatro são PQ2 e um é sênior.

Constatada a existência de um quantitativo representativo de obras dos próprios PQ-CNPq no quadro de textos mais citados, produziu-se a Tabela 1, exibindo o quadro de citações baseado nas 11 obras dos PQ-CNPq que figuram 

da área de Ciência da Informação: um estudo sobre os bolsistas de produtividade em pesquisa (PQ-CNPq) Leilah Santiago Bufrem, Fábio Mascarenhas e Silva, Natanael Vitor Sobral

entre as 35 mais citadas do estudo. O conjunto delas recebeu 203 citações. Dessas, $39,4 \%$ são citações realizadas pelos próprios PQ-CNPq que escreveram as obras, enquanto que 60,6\% foram realizadas pelos pares, o que demonstra um grau razoável de reconhecimento dos $\mathrm{PQ}-\mathrm{CNPq}$ às obras dos seus congêneres, evidenciando que em certos contextos os próprios PQ-CNPq são influências intelectuais de seus colegas.

Tabela 1 - Citações nas 11 obras mais citadas dos PQ-CNPq.

\begin{tabular}{c|c|c|c}
\hline PQ-CNPq & $\begin{array}{c}\text { Citações } \\
\text { Recebidas }\end{array}$ & $\begin{array}{c}\text { \% de Citações realizadas pelo } \\
\text { próprio PQ-CNPq a sua obra }\end{array}$ & $\begin{array}{c}\text { Variedade de PQ-CNPq } \\
\text { que citaram a obra* }\end{array}$ \\
\hline A24 (2001) & 22 & $50,0 \%$ & 8 \\
\hline A16 (2003) & 21 & $9,5 \%$ & 8 \\
\hline A02 (2001) & 20 & $100,0 \%$ & 1 \\
\hline A04 (1994) & 19 & $21,0 \%$ & 9 \\
\hline A05 (2003) & 19 & $78,9 \%$ & 2 \\
\hline A02 (2004) & 18 & $88,8 \%$ & 1 \\
\hline A04 (1996) & 17 & $0,0 \%$ & 5 \\
\hline A17 (1994) & 17 & $11,7 \%$ & 7 \\
\hline A23 (2001) & 17 & $35,2 \%$ & 5 \\
\hline A15 (1997) & 17 & $23,5 \%$ & 4 \\
\hline A09 (2008) & 16 & $68,7 \%$ & - \\
\hline Total & $\mathbf{2 0 3}$ & $\mathbf{3 9 , 4 \%}$ & 5 \\
\hline
\end{tabular}

Fonte: Dados da pesquisa.

* Obs.: neste quantitativo, o PQ-CNPq que escreveu a obra não foi considerado.

Nota: Em um caso específico, por motivo de coautoria com outro PQ-CNPq, mesmo o A02 tendo sido responsável por $100 \%$ das citações a sua obra, uma citação de outro PQ-CNPq foi computada.

Adiante, buscou-se analisar por meio da associação entre palavras-chave e obras citadas (ver Figura 2) o contexto temático em que as influências intelectuais eram referenciadas. Destarte, percebeu-se que os dez temas mais representativos citados pelos PQ-CNPq foram: Tecnologias da Informação e Comunicação (64), Biblioteca (49), Indexação (34), Bibliometria (32), Redes Sociais (32), Arquivos (31), Biblioteconomia (31), Organização do Conhecimento (31), Produção Cientifica (30) e Conhecimento (27). 

da área de Ciência da Informação: um estudo sobre os bolsistas de produtividade em pesquisa (PQ-CNPq) Leilah Santiago Bufrem, Fábio Mascarenhas e Silva, Natanael Vitor Sobral

Figura 2 - Relações entre as dez obras mais citadas pelos PQ-CNPq e os 30 temas mais frequentes.

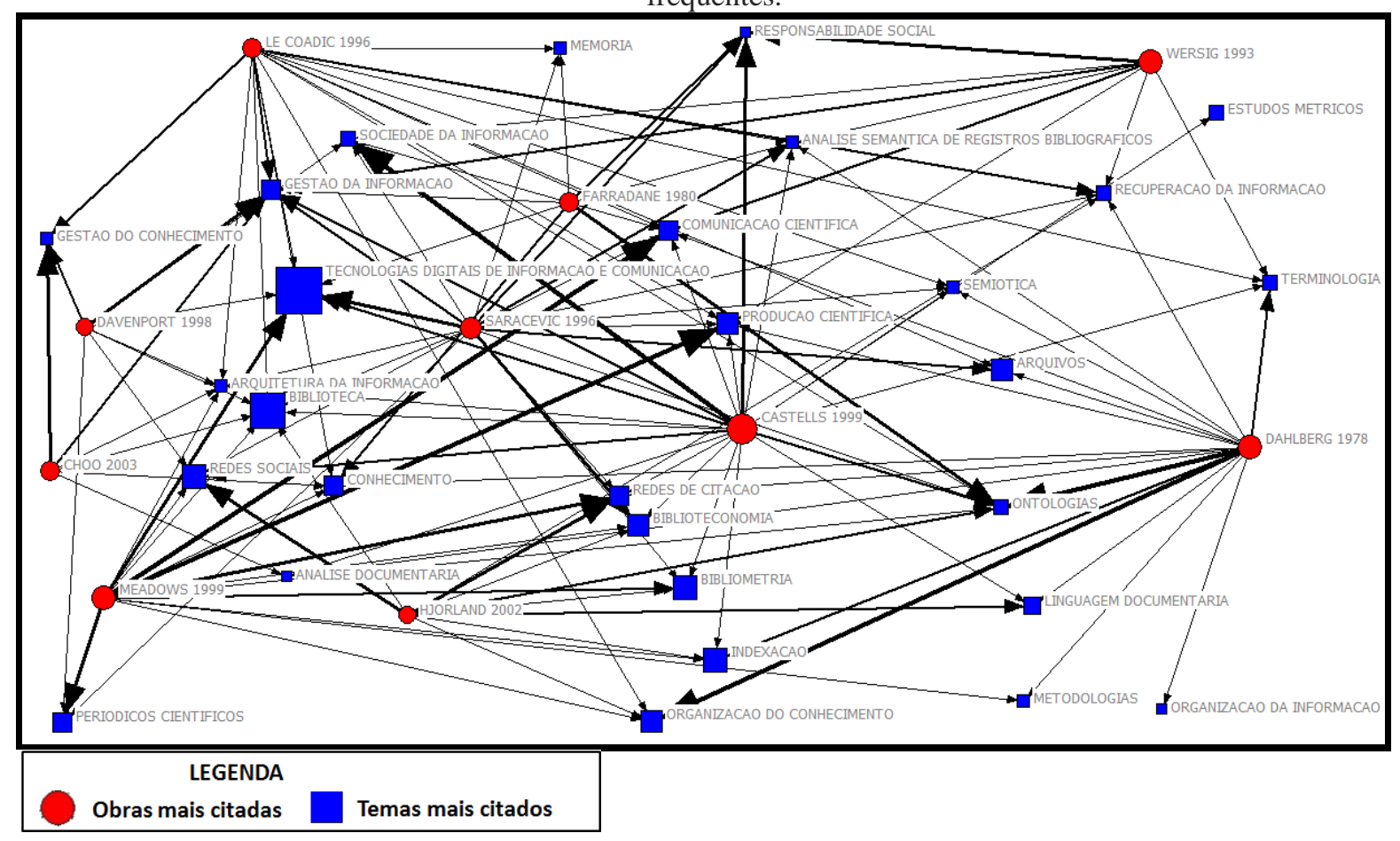

Fonte: Dados da pesquisa.

Dentre as dez obras mais citadas, os vínculos caracterizados como mais estreitos com determinados temas foram: Dahlberg (1978) / Ontologias (oito relacionamentos), Dahlberg (1978) / Organização do Conhecimento (sete relacionamentos), Meadows (1999) / Comunicação Científica (sete relacionamentos), Meadows (1999) / Produção Científica (sete relacionamentos), Castells (1999) / Sociedade da Informação (sete relacionamentos), Saracevic (1996) / Tecnologias da Informação e Comunicação (seis relacionamentos), Davenport (1998) / Gestão da Informação (cinco relacionamentos) e Wersig (1993) / Responsabilidade Social (cinco relacionamentos). Assim, percebe-se a consagração como autoridade dos autores citados nesses temas, a partir das publicações dos PQ-CNPq.

A posição "notável” de Dahlberg (1978), reconhecida como uma das representantes da linha que ela própria denomina como "conhecimento em ação" (DAHLBERG, 1993), decorre de uma concepção de conhecimento distinta da dimensão do conhecimento individual. Ela se volta à ideia do consenso social, um 

da área de Ciência da Informação: um estudo sobre os bolsistas de produtividade em pesquisa (PQ-CNPq) Leilah Santiago Bufrem, Fábio Mascarenhas e Silva, Natanael Vitor Sobral

conhecimento registrado e socializado para que a partir dele, possa ser gerado novo conhecimento, conformando-se, desse modo, uma concepção social, materializada e cíclica de conhecimento (GUIMARÃES, 2001). Essa concepção de Dahlberg (1978) está presente nos dois conjuntos temáticos relacionados à ontologia e à organização do conhecimento, e para seu estabelecimento a autora apresenta categorias representativas de contextos para então analisá-los relacionando os conceitos, a fim de ordená-los no interior dessas categorias.

A posição de Meadows (1999), entre os autores notáveis, é evidenciada de modo especial pelos seus estudos relativos à produção e à comunicação científicas. Sua obra (MEADOWS, 1999) retoma as origens dos modos de comunicar a ciência, desde suas modalidades oral e epistolar, passando pelas associações científicas, que lançam os primeiros periódicos, até as atuais formas de sua produção. O modo de analisar o processo evolutivo dessas manifestações, embora com características positivistas, coincide com as preferências dos autores do universo dessa pesquisa, especialmente no que se refere ao histórico das modalidades objetivas de exposição, assim como das relações presentes na trajetória acadêmica dos pesquisadores, diante dos mecanismos de avaliação e da concorrência interpares.

Castells (1999), por sua vez, citado mais expressivamente em artigos sobre sociedade da informação, se destaca pela sua descrição do cenário mediado pelas tecnologias de informação e comunicação e de suas influências nas estruturas sociais. Ao lançar o conceito de capitalismo informacional, Castells (1999) parte do desenvolvimento das tecnologias e de seus impactos nos diversos campos das relações humanas, em período de reestruturação capitalista. As citações a sua obra são preferidas por pesquisadores que tratam das conformações da nova sociedade e a influência das tecnologias na reestruturação de organizações, de modo especial, por meio das Tecnologias da Informação e Comunicação, afetando a questão da produtividade. Ressaltam também o impacto da reestruturação do capital nas políticas de instituições e organizações, assim como nos níveis de qualificação e de retribuição de empregos. Esse amplo espectro temático encontra em pesquisadores da CI expressivo acolhimento, não somente no que se refere aos 

da área de Ciência da Informação: um estudo sobre os bolsistas de produtividade em pesquisa (PQ-CNPq) Leilah Santiago Bufrem, Fábio Mascarenhas e Silva, Natanael Vitor Sobral

estudos contextuais, culturais, políticos e históricos sobre as questões relativas à informação e às redes sociais, como também em análises sobre os processos de comunicação e as relações verificadas no ambiente multimídia.

A presença de Saracevic (1996) está relacionada à produção científica em CI, principalmente em torno do tema Tecnologias da Informação e Comunicação. A origem, a evolução e as relações presentes nesse campo são consideradas a partir dos problemas, ou recortes de qualquer assunto ou disciplina. Ao afirmar que um campo é definido “[...] pelos problemas que são propostos [...]”, ele utiliza a noção de campo para definir a CI "[...] englobando, tanto a pesquisa científica quanto a prática profissional, pelos problemas que propõe e pelos métodos que escolheu, ao longo do tempo, para solucionar [...]" (SARACEVIC, 1996, p. 41). O autor é citado especialmente quando se refere às características gerais que constituem a razão da existência e da evolução da CI.

A presença de Davenport (1998) se relaciona ao tema Gestão da Informação, com foco no que ele denomina de "relações entrecruzadas" que se verificam entre pessoas, processos, estruturas de apoio e demais elementos do ambiente informacional de uma empresa. A ecologia da informação, como forma de administração holística da informação ou administração informacional, tem como centro o ser humano. É essa especificidade da teoria de Davenport (1998) que, embora considerando a importância da tecnologia, a coloca na periferia, ou seja, no seu devido lugar. E também é essa a motivação para a seleção de sua obra na produção aqui analisada.

Quanto a Wersig (1993), seu nome está vinculado a questões éticas e de responsabilidade social da CI, em decorrência das perspectivas que se voltam à resolução de problemas internos ao campo científico, devido às complexidades e contradições presentes nas situações sociais. Essas contradições, na perspectiva de Wersig (1993), transformam o foco das pesquisas científicas, que passam da descrição para a solução de problemas relacionados ao uso do conhecimento com base nas condições pós-modernas da informatização. (WERSIG, 1993).

Compõe-se, desse modo, uma teia temática que se organiza a partir do conjunto dos pesquisadores em foco, cuja construção sugere a diversidade de 

da área de Ciência da Informação: um estudo sobre os bolsistas de produtividade em pesquisa (PQ-CNPq) Leilah Santiago Bufrem, Fábio Mascarenhas e Silva, Natanael Vitor Sobral

opções temáticas na unidade de um campo de conhecimento e ação que se institucionaliza.

\section{Considerações finais}

Este artigo buscou investigar as bases intelectuais dos PQ-CNPq da área de CI por meio das citações na Brapci. Verificou-se que as obras de Castells (1999), Dahlberg (1978), Wersig (1993) e Meadows (1999) são as mais referenciadas pelos pesquisadores estudados. Ao recortar as 35 obras mais citadas, percebeu-se que aproximadamente $2 / 3$ são de origem estrangeira, o que demonstra o peso da literatura internacional como referencial do grupo. Destaca-se o fato de 11 das 35 obras mais citadas $(31,4 \%)$ serem pertencentes aos próprios PQ-CNPq, sendo que 60,6\% das citações a essas obras foram realizadas pelos congêneres de bolsa, o que sugere a existência de reconhecimento mútuo entre os pares, além de uma expressiva valorização da literatura do próprio país.

Percebeu-se que Tecnologias da Informação e Comunicação, Biblioteca, Indexação e Bibliometria são os temas mais representativos, e que a obra de Dahlberg (1978) é a de maior influência nos trabalhos ligados às Ontologias e à Organização do Conhecimento.

Como fator limitante, destacam-se as recentes mudanças tecnológicas realizadas na Brapci, o que implicou maior empenho na recuperação de alguns artigos, reforçando a necessidade de eliminação de dados duplicados e intensa padronização de registros. As expectativas de aprofundamento deste projeto contemplam a adequação ao universo de PQ-CNPq em CI mais recente, e o mapeamento das influências intelectuais e acadêmicas desse universo.

\section{Financiamento}

Este trabalho foi financiado pelo CNPq com apoio de uma Bolsa de Produtividade em Pesquisa 1D - CA AC. 

da área de Ciência da Informação: um estudo sobre os bolsistas de produtividade em pesquisa (PQ-CNPq) Leilah Santiago Bufrem, Fábio Mascarenhas e Silva, Natanael Vitor Sobral

\section{Agradecimentos}

Agradecemos ao Laboratório Otlet CI da Universidade Federal de Pernambuco pelo suporte nas atividades de tratamento de dados.

\section{Referências}

ANDRAOS, J. Scientific genealogies of physical and mechanistic organic chemists. Canadian Journal of Chemistry, Ottawa, v. 83, n. 9, p. 1400-1414, 2005 .

ARAÚJO, C. A. A. et al. A ciência da informação na visão dos professores e pesquisadores brasileiros. Informação \& Sociedade, João Pessoa, v. 17, n. 2, p. 95-108, 2007. Disponível em:

<http://www.ies.ufpb.br/ojs/index.php/ies/article/view/637>. Acesso em: 10 set. 2016.

BOURDIEU, P. A economia das trocas simbólicas. São Paulo: Perspectiva, 1987. $361 \mathrm{p}$.

BOURDIEU, P.; PASSERON, J.-C.; CHAMBOREDON, J. C. Le métier de sociologue. Paris: Mouton-Bordas, 1969. 328 p.

BRAGA, G. M. Informação, ciência, política científica: o pensamento de Derek de Solla Price. Ciência da Informação, Brasília, v. 3, n. 2, p. 155-177, 1974.

BRASIL. Ministério da Ciência, Tecnologia e Inovação. Conselho Nacional de Desenvolvimento Científico e Tecnológico. Critérios de Julgamento dos Comitês de Assessoramento. 2015. Disponível em: <http://cnpq.br/criterios-dejulgamento>. Acesso em: 1 abr. 2016.

BURKE, P. A social history of knowledge II: from the encyclopaedia to Wikipedia. Cambridge: Polity, 2012.

CASTELLS, M. A sociedade em rede. São Paulo: Paz e Terra, 1999.

CASTELLS, M. Relative ranking of a selected pool of leading communication scholars by number of citations in the Social Science Citation Index, 20002015. 2016a. Disponível em: <http://www.manuelcastells.info/sites/default/files/citation_index_comm_en.pdf>. Acesso em: 10 set. 2016. 

da área de Ciência da Informação: um estudo sobre os bolsistas de produtividade em pesquisa (PQ-CNPq) Leilah Santiago Bufrem, Fábio Mascarenhas e Silva, Natanael Vitor Sobral

CASTELLS, M. Relative ranking of a selected pool of leading scholars in the social sciences by number of citations in the Social Science Citation Index, 2000-2015. 2016b. Disponível em:

$<$ http://www.manuelcastells.info/sites/default/files/citation_index_social_science en.pdf>.Acesso em: 10 set. 2016.

DAHLBERG, I. Knowledge organization: its scopes and possibilities. Knowledge organization, Frankfurt, n. 20, p. 211-222, 1993.

DAHLBERG, I. Teoria do conceito. Ciência da Informação, Brasília, v. 7, n. 2, p. 101-107, 1978.

DAVENPORT, T. H. Ecologia da informação: porque só a tecnologia não basta na era da informação. São Paulo: Futura, 1998.

FRANCK, G. Scientific communication: a vanity fair? Science, Washington, v. 286, n. 5437, p. 53-55, 1999. Disponível em:

<http://science.sciencemag.org/content/286/5437/53>. Acesso em: 1 jul. 2016.

FREITAS, J. L.; NASCIMENTO, B. S.; BUFREM, L. S. A organização do conhecimento na dinâmica da pesquisa em artigos da literatura científica da Brapci. Transinformação, Campinas, v. 26, n. 3, p. 295-303, 2014. Disponível em: <http://periodicos.puccampinas.edu.br/seer/index.php/transinfo/article/view/2633>. Acesso em: 10 set. 2016.

GARFIELD, E. Citation indexes for science: a new dimension in documentation through association of ideas. Science, Washington, v. 122, n. 3159, p. 108-111, 1955.

GUIMARÃES, J. A. C. Perspectivas de ensino e pesquisa em organização do conhecimento em cursos de biblioteconomia: uma reflexão. In: CARRARA, K. (Org.). Educação, universidade e pesquisa. Marília: Unesp-Marília-Publicações; São Paulo: FAPESP, 2001. p. 61-74.

HUTSON, S. R. Self-citation in archaeology: age, gender, prestige, and the self. Journal of Archaeological Method and Theory, [S.1.], v. 13, n. 1, p. 1-18, 2006.

IKEDA, M. et al. An intellectual genealogy graph: affording a fine prospect of organizational learning. In: WORKSHOP ON KM \& OM, 2002. Proceedings... [S.1.: s.n.], 2002. p. 81-87. Disponível em:

$<$ http://www-sop.inria.fr/acacia/WORKSHOPS/ECAI2002-

OM/Actes/ActesECAI2002-OM.pdf\#page=81>. Acesso em: 20 jul. 2016. 

da área de Ciência da Informação: um estudo sobre os bolsistas de produtividade em pesquisa (PQ-CNPq) Leilah Santiago Bufrem, Fábio Mascarenhas e Silva, Natanael Vitor Sobral

JORDAN, K. Visualising the academic genealogy of the Institute of Educational Technology. [S.1.]: The Open University, 2016. Disponível em: $<$ https://www.researchgate.net/profile/Katy_Jordan/publication/304570870_Visua lising the academic genealogy_of the Institute_of_Educational_Technology/lin ks/57739b0d08aeb9427e23dd72.pdf?origin=publication_detail>. Acesso em: 20 jul. 2016.

KROEFF, M. S. et al. Análise de citações dos artigos publicados em periódicos da área da ciência da informação que versam sobre gestão da informação. Revista Brasileira de Biblioteconomia e Documentação, São Paulo, v. 11, n. 1, p. 41-65, jul. 2015. Disponível em: 〈https://rbbd.febab.org.br/rbbd/article/view/301/397>. Acesso em: 15 set. 2016.

LLOYD, C. As estruturas da história. Rio de Janeiro: Zahar, 1995.

LUBEK, I. et al. Faculty genealogies in five canadian universities: historic-graphical and pedagogical concerns. Journal of the History of the Behavioral Sciences, New York, v. 31, n. 1, p. 52-72, 1995.

MACIAS-CHAPULA, C. A. O papel da informetria e da cientometria e sua perspectiva nacional e internacional. Ciência da Informação, Brasília, v. 27, n. 2, p. 134-140, maio/ago., 1998.

MEADOWS, A. J. A comunicação científica. Brasília: Briquet de Lemos/Livros, 1999.

MENA-CHALCO, J. P. Genealogia acadêmica: uma ferramenta para investigar a origem, evolução e disseminação de áreas do conhecimento. In: ENCONTRO BRASILEIRO DE BIBLIOMETRIA E CIENTOMETRIA, 5., 2016, São Paulo. [Workshop] . São Paulo: ECA/USP, 2016. Disponível em:

$<$ https://www.researchgate.net/publication/305082103_Genealogia_academica_u ma_ferramenta_para_investigar_a_origem_evolucao_e_disseminacao_de_areas_d o_conhecimento?channel=doi\&linkId=5781059608ae5f367d392783\&showFullte

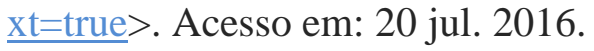

MONTOYE, H. J.; WASHBURN, R. Research quarterly contributors: an academic genealogy. Research Quarterly for Exercise and Sport, Washington, v. 51, n. 1, p. 261-266, 1980.

RADNITZKY, G. Fundamental schools of metascience. Göteborg: Akademiforlaget, 1970. 

da área de Ciência da Informação: um estudo sobre os bolsistas de produtividade em pesquisa (PQ-CNPq) Leilah Santiago Bufrem, Fábio Mascarenhas e Silva, Natanael Vitor Sobral

ROSSI, L.; MENA-CHALCO, J. P. Caracterização de árvores de genealogia acadêmica por meio de métricas em grafos. In: Congresso da Sociedade Brasileira de Computação, 34., 2014, Brasília. Anais... Brasília: SBC, 2014. p. 21-32. Disponível em: 〈http://www.each.usp.br/digiampietri/BraSNAM/2014/p02.pdf〉. Acesso em: 1 jul. 2016.

RUSSELL, T. G.; SUGIMOTO, C. R. MPACT family trees: quantifying academic genealogy in library and information science. Journal of Education for Library and Information Science, Seattle, v. 50, n. 4, p. 248-262, 2009.

SAFER, M. A.; TANG, R. The psychology of referencing in psychology journal articles. Perspectives on Psychological Science, Washington, v. 4, n. 1, p. 51-53, 2009.

SARACEVIC, T. Ciência da informação: origem, evolução e relações. Perspectivas em Ciência da Informação, Belo Horizonte, v. 1, n. 1, p. 41-62, jan./jun. 1996.

SILVEIRA, M. A. A. et al. Domínios científicos da ciência da informação representados no GT 7 do Enancib: análise das citações (2007-2012). Tendências da Pesquisa Brasileira em Ciência da Informação, João Pessoa, v. 6, n. 2, p. 116, 2013. Disponível em:

〈http://inseer.ibict.br/ancib/index.php/tpbci/article/viewArticle/111〉. Acesso em: 1 jul. 2016.

SIRINELLI, J-F. Os intelectuais. In: RÉMOND, R. Por uma história política. Tradução Dora Rocha. 2. ed. Rio de Janeiro: FGV, 2003. p. 231-270.

SMITH, R. Commentary: the power of the unrelenting impact factor: is it a force for good or harm? International Journal of Epidemiology, Oxford, v. 35, n. 5, p. 1129-1130, 2006. Disponível em:

$\langle$ http://ije.oxfordjournals.org/content/35/5/1129.full.pdf>.

Acesso em: 1 jul. 2016.

SUGIMOTO, C. R. Academic genealogy. In: CRONIN, B.; SUGIMOTO, C. R. (Ed.). Beyond bibliometrics: harnessing multidimensional indicators of scholarly impact. Cambridge: The MIT Press, 2014. cap. 19, p. 365-382.

SUGIMOTO, C. R. et al. Academic genealogy as an indicator of interdisciplinarity: an examination of dissertation networks in library and information science. Journal of the American Society for Information Science and Technology, New York, v. 62, n. 9, p. 1808-1828, 2011.

WERSIG, G. Information science: the study of postmodern knowledge usage. Information Processing \& Management, [S.1], v. 29, n. 2, p. 229-239, 1993. 


\title{
Analysis of the intellectual influences on scientific production in the Information Science area: a study on the productivity grants in research (PQ-CNPq)
}

\begin{abstract}
This article investigates the intellectual bases of productivity grants in research of the National Council for Scientific and Technological Development (PQ-CNPq) of the Information Science area through its citations. To compose the corpus of this study, it elects Referential Base of Journal Articles in Information Science, considering the time frame from 1972 to 2015. It adopts as methodological procedures: 1) identification of the productivity grants in research (Information Science); 2) data collection in Referential Base of Journal Articles in Information Science (records plus references); 3) data processing, through its standardization, listing and classification using the VantagePoint software; and 4) analysis and presentation of relationships between citing parties, cited parties and themes. It features among the top results works by Castells (1999), Dahlberg (1978), Wersig (1993) and Meadows (1999) as the most referenced by the investigated researchers. By selecting the 35 most cited works, it notes that approximately two thirds are of foreign origin, which shows the weight of the international literature as a reference group. It notes that 11 of the 35 most cited works $(31.4 \%)$ are from productivity grants in research (Information Science) itself, and $60.6 \%$ of the citations of these works are carried out by scholarship congeners, which suggests the existence of mutual recognition among peers. Finally, it observes that Technology of Information and Communication, Library, Indexing and Bibliometry are the most representative themes, and the work by Dahlberg (1978) is the most influential among studies related to Ontologies and Knowledge Organization.
\end{abstract}

Keywords: Research Productivity. Information Science. Citation Analysis. Intellectual Influences. Scientometrics.

1 BRASIL. Ministério da Ciência, Tecnologia e Inovação. Conselho Nacional de Desenvolvimento Científico e Tecnológico. 2016. Disponível em: 〈http://cnpq.br/>.

2 UNIVERSIDADE FEDERAL DO PARANÁ. BRAPCI: Base de Dados em Ciência da Informação. 2016. Disponível em: <http://www.brapci.ufpr.br/brapci/>.

${ }^{3}$ Dados de 2016.

${ }^{4}$ BRASIL. Ministério da Ciência, Tecnologia e Inovação. Conselho Nacional de Desenvolvimento Científico e Tecnológico. Bolsas. 2016. Disponível em: 〈http://cnpq.br/bolsistas-vigentes〉.

5 SEARCH TECHNOLOGY. VantagePoint: Serious software for serious professionals. 2016. Disponível em: <https://www.thevantagepoint.com/>. Foi utilizada a versão 9.0 do software no Laboratório Otlet CI da Universidade Federal de Pernambuco. 

da área de Ciência da Informação: um estudo sobre os bolsistas de produtividade em pesquisa (PQ-CNPq) Leilah Santiago Bufrem, Fábio Mascarenhas e Silva, Natanael Vitor Sobral

6

ANALYTIC TECHNOLOGIES. UCINET: software. 2016. Disponível em: <https://sites.google.com/site/ucinetsoftware/home>.

${ }^{7}$ THOMSON REUTERS. Web of Science. Social Science Citation Index. 2016. Disponível em: $<$ http://wokinfo.com/products_tools/multidisciplinary/webofscience/ssci/>.

8 ASSOCIAÇÃO NACIONAL DE PESQUISA E PÓS-GRADUAÇÃO EM CIÊNCIA DA INFORMAÇÃO. 2016. Disponível em: 〈http://www.ancib.org.br/>.

Recebido em: 19/09/2016

Aceito em: 08/11/2016 